\title{
Hydrogen Sulfide in Proliferating and Differentiated Cells in Primary Cultures of Juvenile Brain of Masu Salmon Oncorhynchus masou
}

\author{
Evgeniya V. Pushchina1, Sachin Shukla², Anatoly A. Varaksin1 \\ ${ }^{1}$ Zhirmunsky Institute of Marine Biology, Far East Branch, Russian Academy of Sciences, Vladivostok, Russia \\ ${ }^{2}$ Prof. Brien Holden Eye Research Centre, L.V. Prasad Eye Institute, Hyderabad, India \\ Email: puschina@mail.ru
}

Received 28 July 2015; accepted 17 August 2015; published 20 August 2015

Copyright (C) 2015 by authors and Scientific Research Publishing Inc.

This work is licensed under the Creative Commons Attribution International License (CC BY). http://creativecommons.org/licenses/by/4.0/

(c) (i) Open Access

\begin{abstract}
Analysis of proliferative activity and the ability to neuron differentiation was performed in cultured cells of the brain and spinal cord of juvenile masu salmon Oncorhynchus masou. Proliferating cell nuclear antigen (PCNA) was used as a proliferative marker, while the markers of neuronal differentiation-a neuron protein HuCD, and a neuron-specific transcriptional factor with two DNAbinding sites Pax6-detected neurons. The results showed that cell proliferation occurred mainly in the suspension cell fraction. In monolayer, a few cells were only found to express PCNA. The results of morphological and immunohistochemical analysis allow us to conclude that proliferative activity in primary cultures from the $O$. masou brain is mainly connected with the suspension fraction of small cells. In contrast, a positive correlation between the cells expressing cystathionine $\beta$-synthase (CBS), a marker of $\mathrm{H}_{2} \mathrm{~S}$ synthesis, and the cells expressing PCNA in the monolayer, indicates the participation of $\mathrm{H}_{2} \mathrm{~S}$ in proliferative activity of neurons in primary cultures. The data obtained suggest that the hydrogen sulphide is also involved in the process of differentiation.
\end{abstract}

\section{Keywords}

Cell Culture, Fish, PCNA, HuCD, Hydrogen Sulfide, Pax6, Regeneration, Adult Neurogenesis

\section{Introduction}

After injury of the central nervous system, in particular of the spinal cord, the locomotor activity of the fish can effectively recover [1]. It concerns the ability of the central projection neurons to regenerate damaged axons, the 
emergence of new cells in the zone of injury, and the occurrence of high proliferative activity in nearby neurogenic niches and proliferative areas of the brain [2]. Both of these processes, axon regeneration and neurogenesis, contribute to anatomical and functional recovery in the injured CNS of adult fish. Its intrinsic growth and repair capacity, combined with its experimental amenability, present the salmon fishes as a good model for investigations of CNS restoration [3]. However, mechanisms such as high reparative activity in the nervous tissues of fish, including both anatomical and functional regeneration remain poorly explored. Some in vitro model systems have demonstrated their potential for studies on CNS injury and repair [4]. But, so far a model system of adult salmon primary brain neurons has not been described. Here, we report on an in vitro model system of neural cells from masu salmon $O$. masou.

We present morphological data and some cellular characterization supporting the use of this novel in vitro tool in investigations of neurochemical properties, axonal growth and neurogenesis in CNS. For a more detailed study of the properties of cells expressing CBS, their relationship with the cells with different neurochemical specialization in the central nervous system of fish, their characteristics of the processes of proliferation and differentiation, and the features of participation of hydrogen sulfide $\left(\mathrm{H}_{2} \mathrm{~S}\right)$ in reparative neurogenesis, the primary culture of brain and spinal cord from the $O$. masou was set up and properties of proliferation and differentiation were analyzed with the help of specific markers (HuCD, Pax6, CBS, and PCNA).

\section{Materials and Methods}

\subsection{Animals}

The fishes were kept in the standard environment in the aquarium (salinity: $5 \%$, temperature: $15^{\circ} \mathrm{C}-17^{\circ} \mathrm{C}$ ). Five specimens each of the masu salmon, Oncorhynchus masou (in age of one year and four months with the average body length 20 - $22 \mathrm{~cm}$ and average body weight 25 - 30 g) were taken from Rasan fish hatchery (Primorisky region, Russia).

The conditions of the animals were monitored by the aquarium equipment room: the room temperature in the aquarium was maintained by air conditioners. Salinity in water aquariums was created by adding fresh water to sea water with salinity equal to the formation of $5 \%$. The level of salinity of sea water was monitored using a refractometer (Refractometer “AtagoATS-S/Mill-E”, Japan).

\subsection{Primary Culture}

The fishes were sacrificed by decapitation; brain and spinal cord were dissected out aseptically and washed in sterile PBS. The minced tissues were transferred to a sterile $15 \mathrm{ml}$ tube and washed thrice with PBS. In each wash, the pieces were allowed to settle down for some time and the supernatant was discarded. The tissues were then treated with trypsin $(0.25 \%$ and $0.025 \%)$ and collagenase ( $28 \mathrm{U}$ and $56 \mathrm{U})$, incubated in water bath at $28^{\circ} \mathrm{C}$ for 15 minutes, transferred to a $50 \mathrm{ml}$ sterile tube and suspended in a complete growth medium (five times to the volume of the trypsin used): Leibovitz’s L-15 medium containing $10 \%$ fetal bovine serum and 0.4\% (v/v) penicillin/streptomycin antibiotic cocktail (Gibco, Invitrogen, USA). A single cell suspension was prepared by disaggregation. The resulting suspension was allowed to stay in the centrifuge tube for 5 minutes, followed by careful aspiration of the floating cell clumps with the aid of pipette. The suspension was centrifuged at $200 \times \mathrm{g}$ for 5 minutes, the supernatant was discarded and the pellet was resuspended in the complete L-15 medium. The resulting cell suspensions from brain and spinal cord were seeded in the small (35 mm) specially coated duplex dishes and maintained in the incubator at $28^{\circ} \mathrm{C}$ for $3-4$ days for further proliferation and differentiation. Cells were regularly monitored under the microscope (Axiovert Apotom 200 M, Carl Zeiss, Germany).

\subsection{Immunocytochemistry}

After 4 days in culture, the cells from suspension were centrifuged at $250 \times \mathrm{g}$ for 5 min and fixed with $4 \%$ paraformaldehyde for $30 \mathrm{~min}$ at room temperature, followed by a PBS wash. To quench the endogenous peroxidase activity, the cells were incubated with $3 \%$ hydrogen peroxide for 5 min and washed with PBS. To reduce the background staining, cells were incubated with 10\% normal serum in PBS and then with primary antibodies for 1 hour at $37^{\circ} \mathrm{C}$ against PCNA (Santa Cruz Biotechnology; USA; 1:200); Pax6 (Chemicon; USA; 1:300); HuCD (Invitrogen; USA; 1:200); CBS (Abcam; ab54883, UK; 1:200). Cells were gently washed with PBS and incubated for 10 min with diluted biotinylated secondary antibody, followed by a PBS wash. Further staining was 
carried out as described in Vectastain Elite Kit (Vector Laboratories, Burlingame, USA). The microscopic analysis was carried out in duplex dishes under inverted microscope AxiovertApotom 200 M, (Carl Zeiss, Germany).

The cells from suspension population were treated by similar procedure on the glass slidescoated with poly-Llysine. After above mentioned procedure of immunocytochemical labeling, cells from suspension fraction were incubated with peroxidase substrate solution during $10 \mathrm{~min}$. To identify the reaction products, the slices were incubated in a substrate for detection of peroxidase (VIP Substrate Kit; Vector Laboratories, Burlingame, USA); the process of staining was controlled under a microscope. Then, the glass slides were washed out in three changes of phosphate buffer, dried at room temperature, dehydrated using a standard technique, and embedded in medium BioOptica (Italy). To estimate the specificity of the immunocytochemical reaction, we used negative control. The cells were incubated in a medium containing $1 \%$ nonimmune horse serum (instead of primary antibodies) for $2 \mathrm{~h}$, and then all procedures were performed as was described above. In all control experiments, the immunopositivity in the studied cells was absent.

\subsection{Statistical and Morphometric Analysis}

For statistical and morphometric analysis we used software of microscope research class Axiovert $200 \mathrm{M}$ with module Apotome. To do this, were obtained micrograph cell monolayer (for each version of the marking were removed and analyzed 10 non-overlapping fields of view with zoom lens X20). Densitometric investigation of the optical density of immunolabeled cells was performed using software Axiovision in microscope Axiovert. The optical density of immunoprecipitate marked cells were studied on the samples from 50 - 100 cells. Analysis of morphometric parameters of cell culture is given in Table. Data are expressed as the mean \pm S.E.M. and were analyzed with an ANOVA followed by post hoc Tukey's tests unless otherwise stated. P-values $<0.05$ were considered to be statistically significant.

On the basis of morphometric analysis was allocated 5 morphological types of cells in accordance with generally accepted neurohistological classification [5]. The first class was attributed to cells the diameter of which was more than $40 \mu \mathrm{m}$. In second class were cells with the diameter from 20 to $40 \mu \mathrm{m}$, in third class cells with diameter of 15 to $20 \mu \mathrm{m}$, fourth from 10 to $15 \mu \mathrm{m}$, and the fifth class with diameter of less than $10 \mu \mathrm{m}$. Morphometric parameters and correlation study between some of the parameters were analyzed by Microsoft Excel 2010.

\section{Results and Discussion}

Morphometric analysis of dissociated salmon brain and spinal cord cells, grown on laminin coated duplex dishes, revealed 5 morphological types of cells in accordance with classification [5]. In the resulting cultures after four days, most cells were round with a small one, or two processes (Figure 1(A)). We observed that our salmon primary cell culture was heterotypic (consisting of five main types of cells), representing the cellular composition of the adult salmon's brain and spinal cord in the monolayer (Figure 1(A)) and suspension (Figure 1(B)) fractions. Morphometric characteristics of cells are described in Table. Most of the cells in monolayer were round or oval in shape, while some cells were at the initial stage of formation of outgrowths.

In the present study, cells were isolated from the juvenile fishes brain, which, under proper culture conditions, formed neurospheres (Figure 1(C)), contained PCNA-immunolabeled cells (Figure 1(D)) and were self-renewing. We hypothesized that, these cells can be considered as intrinsic stem cells [6]. The intrinsic stem cells are likely to have originated from the proliferation zones in the brain regions contained proliferative zones [7]. In vivo, cells within these proliferation zones in $O$. masou persist during adulthood to undergo mitotic divisions and to produce new neurons [8].

Existing reports about the presence of endogenous sulphides in the brain and about the role of $\mathrm{H}_{2} \mathrm{~S}$ in facilitating the modulation of neuronal activity [9] lead us to analyze the CBS activity in masu salmon's brain.

CBS activity was identified both in cells of suspension fraction and in monolayer (Figure 1(E)). Morphometric parameters of CBS-positive and -negative cells from brain of masu salmon are presented in Table. The vast majority of CBS-positive cells present small cells of the $5^{\text {th }}(84.1 \%)$ and $4^{\text {th }}(14.9 \%)$ types. Thus, the primary culture of the brain and spinal cord of masu salmon contained a heterogeneous population of cells expressing CBS. Cells of the $4^{\text {th }}$ and $5^{\text {th }}$ types in suspension fraction of brain and spinal cord were PCNA-positive. 

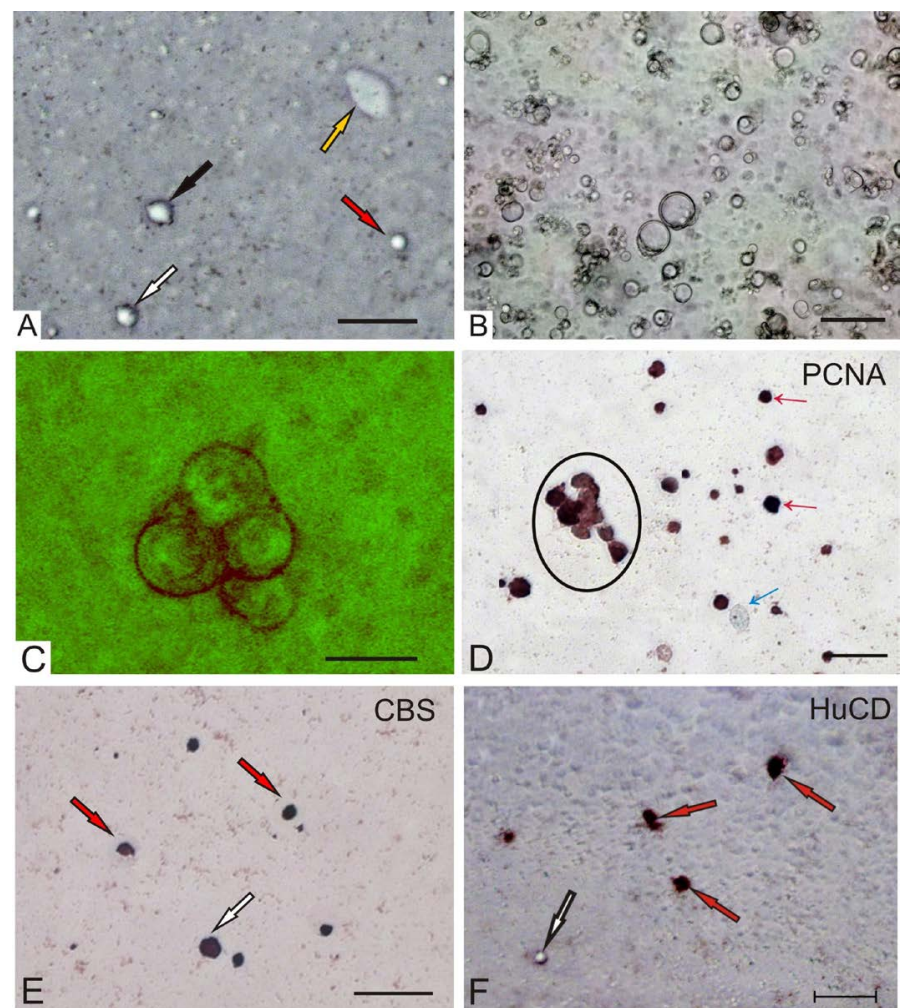

Figure 1. Primary culture of brain cells of masu salmon Oncorhynchus masou. (A) Cells in a monolayer (colored arrows indicate different types of cells); (B) Cells in suspension; (C) Neurosphere; (D) PCNA-immunopositive cells (red arrows) and negative (blue arrow) in suspension, oval contoured conglomerate of PCNA-immunopositive cells (neurosphere); (E) CBS-immunopositive cells of $4^{\text {th }}$ (white arrow) and $5^{\text {th }}$ (red arrows) types; (F) HuCD-immunopositive (red arrows) and negative (white arrow) cells in monolayer. The scale bar: (A), (B), (D)-(F) $50 \mu \mathrm{m}$; (C) $10 \mu \mathrm{m}$.

The data also testify the participation of the transcription factor Pax6 in facilitating proliferation of the cells of the salmon's brain, and suggest $\mathrm{H}_{2} \mathrm{~S}$-dependent mechanisms for such participation (Figure 2). The level of CBS activity in these cells is also high. Thus, the predominant cell type characterized by the highest level of expression of CBS, which were large and medium cells of 1 - 3 types deprived of outgrowths and tended to be grouped into clusters.

Figure 2 shows the results of a quantitative analysis of cells of $4^{\text {th }}$ and $5^{\text {th }}$ types in monolayer immunolabeled with CBS, Pax6 and PCNA that indicate high quantitative correspondence to these types of cells, which indirectly suggest that the small cells, which expressed CBS and Pax6 may be proliferating, and/or out from mitosis cells belonging to the same type. Based on these data, we concluded the existence of a positive correlation between small cells expressing CBS, Pax6 and PCNA in O. masou brain cells.

We then explored the identity of the remaining 39\% non-neuronal (HuCD negative) cells in salmon brain and spinal cord cultures. While neuronal differentiation requires exit from the cell cycle, non-neuronal brain cells, including glia and stem/progenitor cells, are potentially mitotically active. Proliferating cell nuclear antigen (PCNA) is expressed in mitotic cells throughout the cell cycle with prominent nuclear expression [10]. Furthermore, some examples of cytoplasmic immunoreactivity have been reported [11]. Immunocytochemical analysis with anti-PCNA revealed subpopulations of PCNA positive, as well as PCNA negative cells (Table; Figure 1(D)). Thus, the results of morphological and immunohistochemical analysis allow to conclude that: 1) Proliferative activity in primary culture cells in the brain of juvenile masu salmon is mainly present in suspension cell population of $4^{\text {th }}$ and $5^{\text {th }}$ type; 2) There is a positive correlation between cells expressing CBS, Pax6 and PCNA, which indicates the participation of hydrogen sulfide in proliferative activity of cells in postembryonic neurogenesis of masu salmon. 


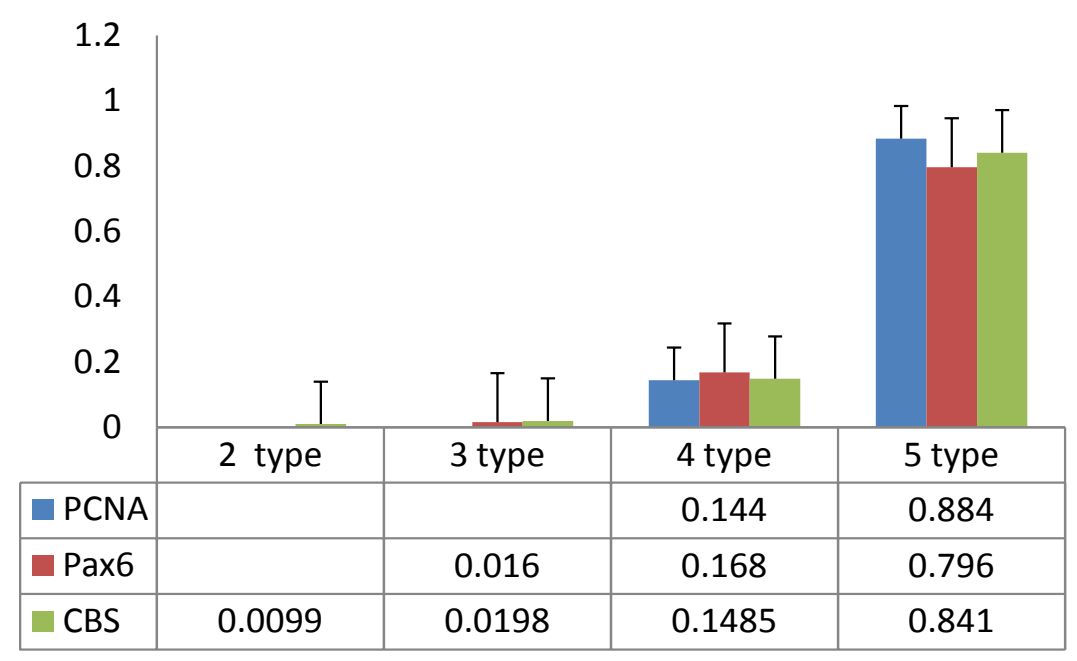

Figure 2. Correlation between expression of HuCD, Pax6 and CBS in cells of monolayer in Oncorhynchus masou brain. Data are shown as $\mathrm{M} \pm \mathrm{m}$. $\mathrm{x}$ - types of cells, $\mathrm{y}$-number of immunopositive cells (\%).

Table. Morphometric characteristic, number and optical density of immunoreactivity of PCNA-, CBS- and HuCD-positive and negative cells $(\mathrm{M} \pm \mathrm{m})$ in monolayer of primary culture of masu salmon Oncorhynchus masou.

\begin{tabular}{|c|c|c|c|c|c|c|c|}
\hline \multicolumn{8}{|c|}{ CBS-positive and negative cells } \\
\hline \multicolumn{4}{|c|}{ CBS-negative cells } & \multicolumn{4}{|c|}{ CBS-positive cells } \\
\hline $\begin{array}{l}\text { Types of } \\
\text { cells }\end{array}$ & $\begin{array}{c}\text { Large diameter } \\
\boldsymbol{\mu \mathbf { m }}\end{array}$ & $\begin{array}{c}\text { Small diameter } \\
\boldsymbol{\mu} \mathbf{m}\end{array}$ & $\begin{array}{c}\text { Percentage } \\
\%\end{array}$ & $\begin{array}{c}\text { Large diameter } \\
\boldsymbol{\mu} \mathbf{m}\end{array}$ & $\begin{array}{c}\text { Small diameter } \\
\boldsymbol{\mu} \mathbf{m}\end{array}$ & $\begin{array}{c}\text { Percentage } \\
\%\end{array}$ & $\begin{array}{l}\text { Optical density } \\
(\mathbf{E} \pm \mathbf{e})\end{array}$ \\
\hline 1 & - & - & - & $45.45 \pm 2.68$ & $38.38 \pm 2.89$ & 15.9 & $142.76 \pm 14.74$ \\
\hline 2 & $24.28 \pm 2.02$ & $22.11 \pm 2.89$ & 13.30 & $31.30 \pm 4.93$ & $26.40 \pm 5.40$ & 66.0 & $160.06 \pm 12.48$ \\
\hline 3 & $17.27 \pm 1.22$ & $14.46 \pm 2.32$ & 18.30 & $18.18 \pm 1.78$ & $14.98 \pm 2.60$ & 11.36 & $144.25 \pm 14.21$ \\
\hline 4 & $12.57 \pm 1.20$ & $10.91 \pm 1.78$ & 48. 3 & 12.8 & 9.85 & 2.27 & $120.9 \pm 10.2$ \\
\hline 5 & $8.75 \pm 0.84$ & $7.69 \pm 0.82$ & 18.30 & $5.9 \pm 1.27$ & $5.5 \pm 0.70$ & 4.50 & $136.2 \pm 11.03$ \\
\hline \multicolumn{8}{|c|}{ PCNA-positive and negative cells } \\
\hline \multicolumn{4}{|c|}{ PCNA-negative cells } & \multicolumn{4}{|c|}{ PCNA-positive cells } \\
\hline 1 & - & - & - & - & - & - & - \\
\hline 2 & $24.66 \pm 1.88$ & $21.14 \pm 2.11$ & 6.7 & - & - & - & - \\
\hline 3 & $17.02 \pm 1.52$ & $15.09 \pm 2.03$ & 15.20 & $16.35 \pm 0.86$ & $14.61 \pm 1.52$ & - & $118.3 \pm 44.74$ \\
\hline 4 & $12.11 \pm 1.36$ & $10.71 \pm 1.71$ & 47.40 & 12.55 & 9.73 & - & $89.95 \pm 5.72$ \\
\hline 5 & $8.80 \pm 0.90$ & $7.93 \pm 0.95$ & 30.50 & $7.55 \pm 1.44$ & $5.98 \pm 0.25$ & - & $82.6 \pm 7.91$ \\
\hline \multicolumn{8}{|c|}{ HuCD-positive and negative cells } \\
\hline \multicolumn{4}{|c|}{ HuCD-negative cells } & \multicolumn{4}{|c|}{ HuCD-positive cells } \\
\hline 1 & - & - & - & - & - & - & - \\
\hline 2 & $22.42 \pm 1.78$ & $19.09 \pm 3.05$ & 5.90 & $21.92 \pm 1.07$ & $16.86 \pm 1.99$ & 12.50 & $121.69 \pm 22.2$ \\
\hline 3 & $17.40 \pm 1.57$ & $12.91 \pm 2.72$ & 11.90 & $17.07 \pm 1.88$ & $13.56 \pm 2.69$ & 31.20 & $120.38 \pm 24.3$ \\
\hline 4 & $11.75 \pm 1.16$ & $9.79 \pm 1.44$ & 44.70 & $12.54 \pm 1.09$ & $9.69 \pm 1.56$ & 56.20 & $102.22 \pm 13.7$ \\
\hline 5 & $8.17 \pm 1.40$ & $6.85 \pm 1.25$ & 37.30 & - & - & - & - \\
\hline
\end{tabular}


Expression of HuCD, a marker of neuro differentiation, in primary culture has shown that this marker is expressed by cells of 2 - 4 types in the masu salmon's brain (Figure 1(F)). Our results indicate that cells exhibit various degrees of maturity in culture. Data suggest that the majority of HuCD positive cells are neuronally committed stem cells or differentiated neurons. In the suspension fraction, this marker was found among small cells that may indicate early neuro differentiation of cells released from the proliferative cycle. Investigation of the correlation relationships between HuCD, Pax6 and CBS-producing cells in the monolayer of masu salmon's brain, showed inverse correlation between the expressions of these markers (Figure 3). Thus, among differentiated populations of large cells of the $2^{\text {nd }}$ type revealed the largest number of CBS- and Pax6-producing cells and the least amount of HuCD-immunopositive cells. Conversely, in the monolayer among small cells of the $4^{\text {th }}$ type, the largest percentage of HuCD-immunopositive and the lowest percentage Pax6 and CBS-producing cells were observed.

Thus, the process of cell differentiation in obtaining primary culture is more characteristic for monolayer. The data obtained suggest that the hydrogen sulphide $\left(\mathrm{H}_{2} \mathrm{~S}\right)$ is also involved in the process of neuronal differentiation; however, the nature of its participation appears to be nonlinear and inversely proportional in terms of mathematical correlations.

An important advantage of our heterogeneous culture system is that it simulates the diverse cellular composition of the juvenile masu salmon brain. Therefore, it may allow cell-cell interactions to occur that play important roles in physiological events such as development or restoration in vivo. However, to answer certain research questions, it may be necessary to isolate specific cellular populations from dissected brain utilizing purification techniques such as fluorescence-activated cell sorting (FACS) or immunopanning. It will be interesting to explore the mechanism behind the participation of $\mathrm{H}_{2} \mathrm{~S}$ in neuronal proliferation and differentiation in correlation with the characteristic markers like PCNA, Pax6 and HuCD. Our further efforts will be directed to understand the underlying mechanism. The potential of our culture system is diverse as it could be used to investigate axonal growth and regeneration, neuronal/glia biology, or stem cell behavior. The neurons in our culture exhibit typical growth and morphological features. Our juvenile masu salmon brain cell culture provides a valuable tool to study numerous developmental and restorative events. Previously, mammalian neuronal cultures provided insight into axon growth mechanisms [12], improved our understanding of regeneration-associated signaling pathways. Due to the intrinsic regenerative capacity of masu salmon CNS neurons in vivo, our system provides opportunity to explore axonal growth and regeneration utilizing a powerful genetic system and the controlled conditions of the culture.

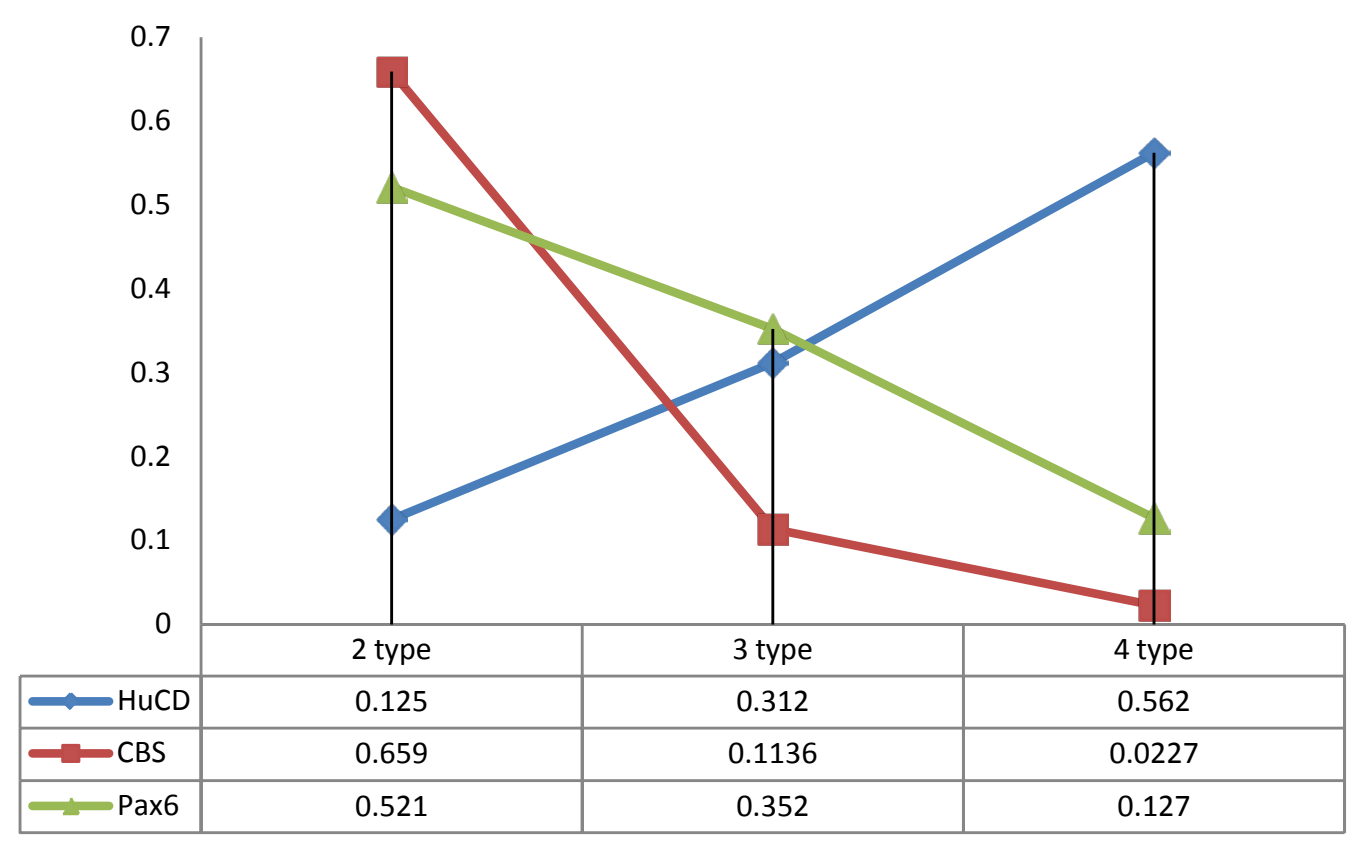

Figure 3. Correlation between expression of PCNA, Pax6 and CBS in cells of monolayer in Oncorhynchus masou brain. $\mathrm{x}$ - types of cells, $\mathrm{y}$-number of immunopositive cells (\%). 


\section{Acknowledgements}

This work was supported by the Grant of President of Russian Federation (MD-4318.2015.4) and DSTINSPIRE Faculty Grant of Government of India (IFA14-LSBM-104).

\section{References}

[1] Kizil, C., Kaslin, J., Kroehne, V. and Brand, M. (2012) Adult Neurogenesis and Brain Regeneration in Zebrafish. Developmental Neurobiology, 72, 429-461. http://dx.doi.org/10.1002/dneu.20918

[2] Becker, T., Wullimann, M.F., Becker, C.G., et al. (1997) Axonal Regrowth after Spinal Cord Transection in Adult Zebrafish. Journal of Comparative Neurology, 377, 577-595. http://dx.doi.org/10.1002/(SICI)1096-9861(19970127)377:4<577::AID-CNE8>3.0.CO;2-\#

[3] Candal, E., Anadon, R., DeGrip, W.J. and Rodriguez-Moldes, I. (2005) Patterns of Cell Proliferation and Cell Death in the Developing Retina and Optic Tectum of the Brown Trout. Developmental Brain Research, 154, 101-119. http://dx.doi.org/10.1016/j.devbrainres.2004.10.008

[4] Sakowski, S.A., Lunn, J.S., Busta, A.S., et al. (2012) A Novel Approach to Study Motor Neurons from Zebrafish Embryos and Larvae in Culture. Journal of Neuroscience Methods, 205, 277-282. http://dx.doi.org/10.1016/j.jneumeth.2012.01.007

[5] Arévalo, R.R., Alonso, J.R., Garcia-Ojeda, E., et al. (1995) NADPH-Diaphorase in the Central Nervous System of the Tench (Tinca tinca L., 1758). Journal of Comparative Neurology, 352, 398-420. http://dx.doi.org/10.1002/cne.903520307

[6] Doe, C.Q., Fuerstenberg, S. and Peng, C.-Y. (1998) Neural Stem Cells: From Fly to Vertebrates. Journal of Neurobiology, 36, 111-127. http://dx.doi.org/10.1002/(SICI)1097-4695(199808)36:2<111::AID-NEU2>3.0.CO;2-4

[7] Zupanc, G.K. and Sîrbulescu, R.F. (2013) Teleost Fish as a Model System to Study Successful Regeneration of the Central Nervous System. Current Topics in Microbiology and Immunology, 367, 193-233. http://dx.doi.org/10.1007/82_2012_297

[8] Pushchina, E.V., Obukhov, D.K. and Varaksin, A.A. (2013) Features of Adult Neurogenesis and Neurochemical Signaling in the Cherry Salmon Oncorhynchus masou Brain. Neural Regeneration Research, 8, 13-23.

[9] Wang, R. (2012) Physiological Implication of Hydrogen Sulfide: A Whiff Exploration That Blossomed. Physiological Reviews, 92, 791-896. http://dx.doi.org/10.1152/physrev.00017.2011

[10] Waseem, N.H. and Lane, D.P. (1990) Monoclonal Antibody Analysis of the Proliferating Cell Nuclear Antigen (PCNA). Structural Conservation and the Detection of a Nucleolar Form. Journal of Cell Science, 96, 121-129.

[11] Vriz, S., Lemaitre, J.M., Leibovici, M., et al. (1992) Comparative Analysis of the Intracellular Localization of c-Myc, c-Fos, and Replicative Proteins during Cell Cycle Progression. Molecular and Cellular Biology, 12, 3548-3555.

[12] Blackmore, M.G., Moore, D.L., Smith, R.P., et al. (2010) High Content Screening of Cortical Neurons Identifies Novel Regulators of Axon Growth. Molecular and Cellular Neuroscience, 44, 43-54. http://dx.doi.org/10.1016/j.mcn.2010.02.002 